\title{
EDUCAR PARA SUPERAR: UMA REFLEXÃO SOBRE A EDUCAÇÃO FÍSICA ESCOLAR
}

\author{
Maria Cecília de Paula Silva*
}

\section{RESUMO}

Este artigo comenta uma diretriz curricular de educação física escolar e suas relações com o atual momento histórico. Consideramos como critérios de análise a dinâmica social e a política local, a relação trabalho-educação e a produção do conhecimento. Compreendese a cultura corporal, seu objeto de estudo e a educação física, disciplina escolar. A proposta aponta para a necessidade urgente e contínua da luta por uma educação pública de qualidade e de uma sociedade diferente da atual, com justiça econômica e social.

PALAVRAS-CHAVE: educação escolar-proposta político-pedagógica - política pública.

\section{INTRODUÇÃO}

\section{SITUANDO O TEXTO NO CONTEXTO}

$\mathrm{O}$ propósito deste artigo é de a partir de uma determinada proposição curricular: "Programa Municipal de Educação Física: diretriz curricular", discutir as possibilidades de aplicação e de superação das atuais práticas educativas desta disciplina escolar. Entendemos ser fundamental este diálogo por considerarmos pertinente explicitarmos pontos relevantes entre a intenção e as possibilidades de ação superadora. Estas considerações são pertinentes no atual momento histórico em que a educação física avança na compreensão de seu pertencimento ao campo de conhecimento das ciências humanas e sociais e neste momento de acirramento da luta por um ensino público de qualidade e para TODOS, em todos os níveis de ensino.

* Professora Adjunta do Departamento de Educação Física da Faculdade de Educação Física da Universidade Federal da Bahia. 
O Programa Municipal de Educação Física de Juiz de Fora (MG) foi escolhido por ser um dos inúmeros exemplos que explicitam certa organização do trabalho pedagógico vinculado a uma perspectiva crítica da educação e ensino (proposta crítico-superadora), além de se constituir numa produção coletiva de professores da rede pública municipal de Juiz de Fora (COLETIVO DE AUTORES, 1992).

Neste programa, propõe-se uma educação física que supere as práticas atreladas unicamente ao paradigma biológico, descontextualizada do social, do político, do econômico e da dimensão de totalidade do ser humano. Não podemos considerar os parâmetros biológicos como norteadores principais (se não únicos) na intervenção escolar desta disciplina.

Entendemos a Educação Física como parte das ciências sociais e humanas, porque aborda o conjunto de expressões humanas constantes nas estruturas, processos, sujeitos, significados e representações produzidas pelas manifestações da expressão corporal como linguagem. Seu objeto é a cultura corporal, parte do acervo da humanidade e por isso indispensável ao conhecimento escolar para o entendimento da realidade social e do mundo do trabalho.

Neste sentido, perspectivamos uma educação para a superação. Acreditamos que estas aproximações, ainda que insuficientes para a transformação pretendida, são importantes para a luta política e ideológica em curso na educação física como campo de conhecimento, auxiliandonos na demarcação/aprofundamento do seu território educacional integrado à realidade.

Além do mais, a educação constitui um campo de lutas de classes, que, por muitos anos no Brasil, perpetuou o analfabetismo entre jovens e adultos oferecendo uma educação precária para crianças e adolescentes ${ }^{1}$. O sistema escolar público marginalizou milhões de crianças das camadas populares com poucas escolas públicas e mínimas condições de ensino. E a educação física serviu como instrumento ideológico no ensino/aprendizagem de comportamentos, atitudes, valores e ações pretendidas para a formação de mão-de-obra barata, de um exército de reserva $^{2}$ : saudável, apto, competitivo e obediente.

Tendo consciência de tal processo, um conjunto de professores da rede municipal resolveu refletir sobre a disciplina Educação Física, sua inserção escolar e a proposição de práticas mais significativas, que abordassem a temática da cultura corporal como diretriz político-pedagógica 
no currículo escolar. De acordo com Paula Silva (1999, p. 2), para "mediatizar o diálogo entre os professores e a comunidade escolar", foi proposta a discussão situada no contexto da população atendida e da reestruturação produtiva da globalização excludente, de crise do trabalho assalariado e de novas formas de alienação do trabalho.

Este entendimento se deu por acreditarmos que, ao contrário dos que defendem o fim do papel central da classe trabalhadora na atualidade, o maior desafio da classe que vive do trabalho é "soldar os laços de pertencimento de classe existentes entre os diversos segmentos que compreendem o mundo do trabalho" (ANTUNES, 2000, p. 171). O trabalho é aqui considerado como a relação fundamental que define o modo humano de existência.

$\mathrm{O}$ estado da arte da educação física escolar municipal refletia a discussão empreendida durante os anos 80 e 90 e as proposições que daí surgiram (CARVALHO, 1991; COLETIVO DE AUTORES, 1992; OLIVEIRA, 1994; CBCE, 1997; TAFFAREL, 2001, entre outros) a respeito da sua prática pedagógica, da legitimidade deste conhecimento na escola e sociedade, e sobre seu objeto. Apesar dos avanços obtidos a partir do debate em torno das abordagens teórico-metodológicas para a Educação Física, problemas centrais como o da identidade pedagógica, autonomia e legitimidade ainda permanecem com consideráveis lacunas relacionadas a sua forma de inserção escolar.

\section{O QUADRO ATUAL DA EDUCAÇÃO E O PROGRAMA MUNICIPAL}

A pertinência e a relevância deste tema para a análise das possibilidades escolares da Educação Física e das discussões a respeito das dificuldades da educação brasileira se reafirmam cada vez com mais força na medida em que avançamos no início deste novo século, com questões como a da formação básica para a classe que vive do trabalho. E mais, com questões como a formação para a superação de uma sociedade em que o controle e a natureza da formação escolar têm ficado nas mãos do capital.

A construção da escola pública unitária e da educação omnilateral aparece como necessidade urgente para a superação de uma educação pautada na lógica do capital, visando a formação subordinada, com delimitação dos conteúdos e da gestão do processo educativo, demarcada 
pela exigência da polivalência ou policognição tecnológica, formação de mão-de-obra barata, de um exército de reserva mais flexibilizado numa perspectiva política utilitarista e intelectualmente limitante (FRIGOTO,1996).

Mais ainda, nestes tempos de hegemonia neoliberal na América Latina e da (im) possibilidade de mudanças com o novo governo brasileiro em curso, confirmamos que a tarefa de democratização da instituição escolar necessita de um esforço conjunto: da sociedade organizada, dos partidos e sindicatos progressistas e dos movimentos sociais (implica a participação do Estado e dos trabalhadores).

Esta articulação foi refletida em Juiz de Fora (MG), no campo da Educação Física especialmente. A cidade possui uma trajetória histórica de lutas no campo educacional com um sindicato de professores forte e um grupo significativo de professores de educação física, que se colocavam explicitamente insatisfeitos com as diretrizes da educação pública. Relacionada à educação física escolar, esta insatisfação foi explicitada e debatida nas reuniões mensais do então Departamento de Educação Física com inúmeras soluções sendo tentadas para afinar a prática pedagógica ao espaço escolar, à proposta político-pedagógica e à política pública municipal.

Apesar de a Educação Física já constar no currículo escolar municipal desde a década de 1970, o eixo norteador de sua prática pedagógica não a legitimava como disciplina escolar, acarretando inúmeros problemas, dentre os quais os relacionados à indefinição de princípios e mínimos curriculares para orientar o trabalho nas escolas.

A reflexão político-pedagógica apontou para novos entendimentos e organizações curriculares, estabelecendo como seu eixo a constatação, a interpretação, a compreensão e a explicação da realidade complexa e contraditória. Ao adotar a proposição crítico-superadora, demarcamos um diferencial importante nestes tempos de globalização da economia e reestruturação produtiva e de exclusão crescente da maioria da população.

É importante frisar a compreensão da Educação Física/Esporte como parte de um projeto político de educação, projeto que representa uma estratégia de "intervenção na realidade social a partir de uma reflexão pedagógica capaz de interpretar as relações sociais de uma sociedade historicamente determinada e interferir no seu desdobramento". Para tal, reconhecemos a realidade como balizadora das decisões científicas e pedagógicas. A opção metodológica na elaboração da proposta considerou as relações de produção da vida, a realidade socialmente 
construída e a cultura popular ${ }^{4}$ como ponto de partida (levantamento das manifestações da cultura corporal nas comunidades/bairros, através de questionários, entrevistas, observações e registros), compromissada com um projeto histórico superador.

A Cultura é entendida como a maneira pela qual os humanos se humanizam por meio de práticas que criam a existência social, econômica, política, religiosa, intelectual e artística. Neste sentido, são constituintes da cultura as instituições sociais (como a escola e a família) e políticas (o Estado), as artes, as danças, os jogos, as festas, as lutas, as atividades esportivas e de lazer, as relações entre os grupos, as formas de se relacionar com o corpo e a sexualidade, entre outras.

Propõe-se o trabalho com a diversidade da turma, abordando os conteúdos de forma a considerar as possibilidades dos alunos, ao invés das suas limitações. Importa mudar os conceitos, atitudes, fixando o olhar para as possibilidades. Respeitar, explicitar, refletir sobre as diferenças de cor, sexo, física, mental, cultural, de classe, trabalhando com elas é um desafio da escola pública, pretendendo a superação das condições desiguais de vida, econômicas e/ou socioculturais.

Entendemos que a educação física - e as demais disciplinas devam ensinar, para além dos conteúdos específicos, a leitura de mundo socializada, a história ligada à origem sociocultural da população, explicitando a luta de classes, os determinantes sociais da educação, preparando para a luta política de resistência ao avanço das políticas neoliberais pelo acirramento da contradição educar/explorar. Freitas (2003) defende que esta luta deve ser explicitada já que o capitalismo volta seus interesses para a preparação de um novo trabalhador mais adequado às exigências do novo padrão de exploração.

A partir de reflexões como estas e frente às possibilidades concretas do coletivo de professores, a perspectiva de currículo ampliado foi considerada por contemplar a ampliação das referências do conhecimento mediada pela formação humana, em que a reflexão pedagógica é elaborada na realidade social através de uma determinada lógica.

Para tal, traçamos como objetivos:

- Ir ao mundo das relações sociais e produtivas concretas para subsidiar a compreensão dos processos pedagógicos escolares e a construção da proposta para os filhos da classe que vive do trabalho e os excluídos deste; 
- Sistematizar um programa de Educação Física de Pré a $8^{\mathrm{a}}$ série na rede Municipal de ensino;

- Estabelecer um eixo norteador de ação para os professores de Educação Física, considerando um mínimo de conhecimento a ser desenvolvido no ensino fundamental;

- Justificar (respaldar) a prática pedagógica dos professores da Educação Física na sua ação cotidiana, nas relações com a escola e com a comunidade.

A compreensão da perspectiva histórica da cultura corporal/esportiva nas relações do homem com o meio ambiente e com os outros homens teve como referência a organização corporal (no espaço/tempo e ações concretas) - intencionalidade - para "manter, produzir e reproduzir a vida, construindo-se significados e significantes subjetivos que se objetivam na expressividade humana corporal e configuram linguagens, níveis e graus de consciência e práticas" (TAFFAREL, 2000, p. 93).

Assim, oportunizam-se aprendizagens significativas para os que as cultivem e transmitam a outras gerações, possibilitando a vivência, historização, reflexão, preservação da cultura e memória e principalmente, a compreensão e desvelamento dos determinismos sociais, dos significados histórico-sociais e a ressignificação de suas práticas: de reprodutivas para críticas, criativas e superadoras.

Em relação à visão biológica da educação física escolar, a concepção adotada na proposta busca romper criticamente com o até então prisma da aptidão física. A reflexão estabelecida no coletivo partiu do conceito diferente da interpretação generalizada pela visão médico/biológica, de atribuição individual e que supõe uma sociedade equilibrada e passível de ser controlada pela vontade pessoal. Contrapondo-se a esta, propõe-se um entendimento que ultrapassa os aspectos bio-fisiológicos, dando abrangência e historicidade (MINAYO, 1999). Os conteúdos - manifestações da cultura corporal - não poderiam ser pensados e nem explicitados isoladamente e, sim, vinculados à realidade social. Esta proposta que parte do entendimento da cultura corporal como uma totalidade formada por distintas práticas sociais - corporais, como o jogo, a ginástica, o esporte, a dança e a luta se diferencia da que historicamente predominou na escola (balizada pelo parâmetro da aptidão física, do rendimento, da saúde).

Alguns autores como Soares (1994), Carvalho (1991), Oliveira (1999) e Paula Silva (2002) consideraram um entendimento diferente do 
da medicalização no trato com as atividades físicas, o entendimento que têm procurado entender o fenômeno da Educação Física e da saúde em suas raízes sócio-históricas.

Entendida como uma questão social, a saúde passa a ser responsabilidade de toda a escola, considerada como uma meta a ser conquistada, como um bem que se adquire através dos conflitos, da luta de classes e de várias formas de reivindicação, não devendo ser compreendidos, no entanto, numa relação de causa-efeito. Neste sentido, frequientar aulas de Educação Física não garante que os alunos se tornem mais saudáveis, mas podem se tornar mais informados e críticos sobre as mistificações sociais e culturais desta relação, e suas desmistificações.

A saúde nesta proposta é um direito coletivo, tema de transformação das condições de vida e de trabalho e que em última instância aponta para transformações do modo de produção e das relações sociais de produção ${ }^{5}$. Saúde não se restringe a cuidados individuais com o corpo e a higiene, mas é um bem coletivo, não se limitando ao contorno corporal individual. O programa propõe desvendar o caráter ideológico da perspectiva de educação física escolar/saúde e o caráter de classe dos investimentos públicos (PAULA SILVA, 2002).

Os objetivos/avaliação consideram tanto as proposições políticas como o princípio teórico/metodológico, na formação humana e na compreensão de sujeito histórico. O par dialético objetivos/avaliação mostra-se importante por demarcar os limites/possibilidades da escola no presente momento explicitando as contradições, pois "o capitalismo está diante de uma contradição entre o nível de instrução da força de trabalho e as novas formas de exploração da força de trabalho" (FREITAS, 2003, p. 258).

A perspectiva adotada deriva da própria materialidade das relações sociais de classe e inclui a concepção mais totalizante do homem como corpo/alma, matéria/espírito, as relações afetivas e as condições de vida e trabalho. Esta perspectiva é mediada pelo pressuposto do trabalho como criador da condição humana e pelas mediações que alienam, transformando-o em mercadoria e força de trabalho. Nesta compreensão, trabalho e relações materiais de produção são fundantes do humano, pois é pelo trabalho que esta espécie se produz. 


\section{TRABALHO-EDUCAÇÃO}

Tomar a realidade atual como norteadora do ensino e do trato com o conhecimento implica entendê-la no contexto dos conflitos sociais da luta de classes que, historicamente tem determinado para a classe trabalhadora a "perda do direito ao trabalho, a terra, à saúde, o recrudescimento do analfabetismo e da violência, a mortalidade por doenças decorrentes da destruição do meio ambiente e outros" (TAFFAREL, 2000, p. 93).

Enquanto relação social fundamental que define o modo humano de existência, o trabalho não se reduz à atividade de produção material para responder à reprodução físico-biológica (mundo da necessidade), mas envolve as dimensões sociais, estéticas, culturais, artísticas, de lazer, etc. (mundo da liberdade). A adoção deste conceito implica na superação da visão do trabalho como coisa, como objeto, visão social hegemônica. Na sociedade atual, a concepção burguesa de trabalho construída historicamente o reduz a uma coisa, um objeto, estruturando uma representação de trabalho igualada à ocupação, emprego, função, tarefa, dentro de um mercado, perdendo-se assim a compreensão de que o trabalho é uma relação social e que esta relação, na sociedade capitalista, é uma relação de força, de poder e de violência.

Relação esta que gera problemas como a alienação do homem de sua condição de sujeito histórico, de uma privação da própria essência do homem, em que a sua liberdade formal se converte em escravidão, ou no pressuposto de que ele seja substancialmente não livre.

O não entendimento do trabalho como produção humana ocasiona problemas que devem ser combatidos com questões como a compreensão da educação e do trabalho como atividade sensível. A chave para se compreender a história humana prende-se aos desejos materiais dos homens, à realidade; "a forma como o homem produz determina seu pensamento e seus desejos; refere-se ao modo de produção; não a um fator subjetivo, psicológico, porém, objetivo, econômico, social" ${ }^{6}$.

Para se explicitar a relação trabalho-educação, precisa-se repensar a especificidade da escola a partir de determinações fundamentais como as relações sociais de trabalho, as relações sociais de produção, distinguindo o projeto capitalista do projeto progressista, pois "somente assim poderemos aproveitar as contradições do sistema capitalista, em benefício das classes populares, e evitar a ingenuidade e a cooptação" (FRIGOTTO, 2001, p. 41).

212 PAULA SILVA, M. C. Educar para superar: uma reflexão sobre a educação ... 
A escola que queremos é uma escola de qualidade para todos. Nestes termos, o projeto histórico alternativo foi nosso ponto de partida e o trabalho como criação, produção da vida, trabalho e lazer, o centro.

Atualmente convivemos com a crise do trabalho assalariado ${ }^{7}$ constituindo-se num dos problemas políticos mais agudos da história da humanidade, paralelamente com uma profunda contradição: a classe trabalhadora, que sempre lutou pela redução da jornada de trabalho e liberação do tempo livre, vive o desespero de ter que se manter empregada mesmo às custas da perda de direitos conquistados duramente pelos trabalhadores e organizações de classe. Diversos estudiosos ${ }^{8}$ entendem que certamente há uma mudança enorme das formas de trabalho, que o trabalho produtivo direto diminuiu e cresceu o setor de serviços, diminuindo o poder de foco dos sindicatos. Mas o trabalho ainda não perdeu sua centralidade e a busca de alternativas societárias de novo tipo permanece.

Os processos educativos e formativos que são constituintes e constituídos das relações sociais passam por uma ressignificação no campo das concepções e das políticas. Neste quadro, o trabalho deve se destacar como sendo um princípio educativo - de um pressuposto ético-político de que os seres humanos têm a necessidade de alimentar-se, proteger-se e criar seus meios de vida. Deve-se, pois, "socializar, desde a infância, o princípio de que a tarefa de prover a subsistência, pelo trabalho, é comum a todos os seres humanos, é fundamental para não criar indivíduos, ou grupos, que exploram e vivem do trabalho de outros" (FREITAS, 2003, p. 128).

Para enfrentarmos o desafio atual, estratégias de políticas públicas com questões concretas e imediatas relativas à educação básica se tornam urgentes de serem efetivadas. $\mathrm{O}$ projeto esboçado foi proposto e desenvolvido no município em 1999. O resultado da primeira parte publicado em forma de livro ${ }^{9}$ - expressa a ação coletiva de um grupo de professores, bem como a dinâmica complexa e contraditória da sociedade. Destaca-se o caráter inovador desta perspectiva, constituída como prática política (na proposição anunciada e na viabilização da mesma).

Entretanto, os desdobramentos atuais expressam o contexto de embates que se travam hoje na sociedade brasileira na busca de romper com todas as formas de exclusão social. Infelizmente, a lógica do capital (hegemônica) e a perspectiva reducionista permanecem na escola pública municipal materializadas nos "Eixos Organizativos do Trabalho da Rede 
Municipal de Educação-Juiz de Fora"10 , aprovados em 2003 e que coloca a educação física, educação artística e literatura como conhecimentos pertencentes ao eixo complementar e não ao fundamental do currículo escolar. Organização que retorna à lógica cartesiana, dual e subordinada entre teoria/prática; corpo/mente; intelectual/corporal; trabalho manual/ trabalho intelectual, racional/ emocional.

Este entendimento é um claro retrocesso de conquistas históricas dos professores de Educação Física e Educação Artística, por exemplo, na sua luta por um trabalho digno, de qualidade e fundamental na Educação. É também um equívoco em relação ao trato com o conhecimento escolar que subordina certos conhecimentos a outros, ditos "mais importantes" (sic), denominando-os de "fundamentais" e "complementares" (PAULA SILVA, 2004, p. 64).

Ao compreendemos os conhecimentos escolares (entre eles a Educação Física, Educação Artística, Literatura) como indispensáveis para o entendimento da realidade enquanto totalidade, eles se tornam fundamentais no ensino público em geral e, particularmente, para a GEB/ JF. Necessita-se da re-organização da luta histórica dos professores para que o programa avance, através da práxis pedagógica e política.

$\mathrm{Na}$ ação pedagógica e na intervenção política materializadas pela ação no chão da escola e na luta pela modificação do organograma, considerando estas disciplinas como fundamentais, articuladas a outras por uma perspectiva interdisciplinar; e não de forma fragmentada, reducionista, subordinada, desigual.

\section{A EDUCAÇÃO FÍSICA ESCOLAR E A PRODUÇÃo DO CONHECIMENTO}

As reflexões desenvolvidas auxiliaram-nos tanto na sistematização dos conhecimentos trabalhados no espaço escolar como na tomada de consciência, da forma mais ampla possível, da realidade histórica para que se constituísse em elemento de ação pedagógica e de ação política, principalmente. Consideramos fundamentais as esferas e dimensões do conhecimento que são parte da cultura corporal/esportiva.

A perspectiva histórica da luta de classes incorporada ao contexto educacional possibilita o reconhecimento da identidade cultural e sóciopolítica, através do reconhecimento e valorização das diversidades 
socioeconômicas, regionais e culturais das comunidades da escola pública, da sua apropriação crítica e da possibilidade de sua transformação. O conhecimento expressa um dos modos de apropriação do mundo pelo homem, possibilitada pela atividade humana frente à realidade.

Para tal, o indivíduo insere-se no meio histórico-cultural, compreende-se como sujeito histórico, construtor de seu tempo e de sua história, possibilitando uma melhor intervenção social. Não uma intervenção qualquer, e sim situada em prol do desenvolvimento de uma escola unitária, no chão da escola e na luta contra-hegemônica, partindo "de uma construção molecular, orgânica, pari passu à construção da própria sociedade no conjunto das práticas sociais" (KOSIK, 1995, p. 35).

Possibilitar, para além da reprodução do conhecimento, uma produção do mesmo como práxis transformadora, tendo a superação histórica do capitalismo como horizonte e não apenas como contemplação (para uma parte do coletivo de professores); ou a produção de novas práticas pedagógicas tendo em vista a proposição desta alternativa pedagógica escolar comprometida com a classe que vive do trabalho e com uma sociedade mais justa e igualitária (para outra parte deste coletivo de professores).

Entendemos também que esta, como qualquer outra iniciativa de orientação técnica e científica para o setor educacional, tem de ser acompanhada de uma política ampliada que contemple as condições de trabalho, o salário, as necessidades de uma política de educação continuada dos educadores e, finalmente (para alguns do grupo), a transformação do modelo de sociedade atual, em busca da efetiva valorização do ser humano, do professor, da escola pública, da classe que vive do trabalho, pautando-se na produção do conhecimento da práxis social brasileira.

Este projeto significa, por fim, o ponto de início para a reflexão constante em torno do conhecimento na escola, compreendendo a educação física como parte integrante do processo educacional escolar, indispensável para a formação do ser humano e para o entendimento e intervenção na e da realidade em sua totalidade.

Significa igualmente uma possibilidade de resgate da qualidade da escola pública e de uma educação para a cidadania, e conforme Franco (1998, p. 35), "com dimensões mais amplas que o horizonte do mercado e da produção para a competitividade" nesta sociedade ainda fortemente injusta e desigual, pretendendo a transformação da realidade excludente em relações mais justas, democráticas, igualitárias. 
Para além das teorizações abstratas e da prática pela prática, consideramos o desafio de reconhecer os núcleos centrais de conhecimentos socialmente relevantes que se relacionem à especificidade das práticas corporais geradoras de conhecimentos específicos articulados aos gerais críticos e reflexivos.

O desafio de afirmar a função social escolar como espaço de formação humana de classe, compromissada com a mudança e de construirmos uma escola pública e unitária que atenda à classe proletária de uma educação omnilateral ${ }^{11}$, buscando uma totalidade de capacidades ao tempo em que oportunize a possibilidade de usufruto dos bens materiais e dos bens espirituais.

Na rede municipal, o desafio imediato é político e pedagógico: o fortalecimento de nossa organização sindical para a luta por melhores condições de trabalho na educação. Na Educação Física, além desses, o desafio que se mostra urgente é o de retornar a nossa luta histórica pela legitimidade deste fundamental conhecimento escolar.

Uma das formas para tal é a mobilização para o embate políticopedagógico e a retomada da proposta sistematizada pelo coletivo de professores municipais, no sentido de ampliá-la, aprofundá-la, integrá-la aos outros conhecimentos e ao cotidiano escolar para superá-la permanentemente, num movimento dinâmico, dialético e histórico.

O desafio é, por fim, a construção coletiva de uma política pública compromissada com a classe que vive do trabalho e com uma educação pública de qualidade, de uma educação que, sustentada na práxis social, dê subsídios para superar as desigualdades e o sistema perverso atual.

\title{
Educating to overcome: A reflection upon Physical Education in schools
}

\begin{abstract}
This article comments on a syllabus directive for physical education in schools and its relations with our current historical moment. We consider social dynamics and local policies, the relationship between work and education, and the production of knowledge to be the criteria for analysis. We understand body culture to be the object of study and physical education to be a school subject. The proposition points to the urgent and continuous need for standing for quality public education and for a society that is different from the current one, with economic and social justice.
\end{abstract}

KEY-WORDS: school education - political - pedagogical propositon - public policies. 


\section{Educar para superar: Una reflexión sobr e la}

Educación física escolar

\section{RESUMEN}

Este artículo comenta una directriz curricular de educación física escolar y sus relaciones con el actual momento histórico. Consideramos como criterios de análisis la dinámica social y la política local, la relación trabajo-educación y la producción del conocimiento. Comprende la cultura corporal su objeto de estudio y la educación física, asignatura escolar. La propuesta señala la necesidad urgente y continua de la lucha por una educación pública de cualidad y de una sociedad diferente de la actual, con justicia económica y social. ualidad e de una sociedad diferente le la actual, con la igualdad económica e social. PALABRAS-CLAVE: educación escolar-propuesta político-pedagógica-política pública.

\section{NOTAS}

1 Trabalhos como o de Freire (1993) retratam este quadro historicamente. Kuenzer (1987), Frigotto (1996) definem a formação hegemônica do ensino público.

2 Cf. Kuenzer (1988); Frigotto (1995; 2001a); Neves (2000).

Paula Silva (2003, p. 77) na linha argumentativa de Escobar; Taffarel; Soares (1995).

4 O que define a cultura popular aqui considerada é a consciência de que "ela tanto pode ser um instrumento de conservação como de transformação social" (CULLAR, 1990, p. 50).

5 Melhores salários, acesso a terra, a empregos, a saneamento básico, a transporte, a moradia, a educação, a lazer e a condições de trabalho seguras.

6 O trabalho aqui é considerado por Kosik (1995) como um processo que permeia todo o ser do homem constituindo a sua especificidade.

7 Entendida como aumento exponencial do desemprego estrutural e precarização do trabalho, de acordo com Frigotto (2001b).

8 Forrester (1997); Oliveira (1999); Hobsbawm (2000); Meszáros (2003); Sader (2003).

9 Paula Silva; Zacarias (2000).

10 Ver p. 89 da rev. Cadernos para o Professor (ANEXOS, 2003). Perspectiva Tradicional do conhecimento escolar, baseada na lógica formal e no pensamento cartesiano.

11 Cf. Marx \& Engels (1978; 1999); Manacorda (1991), por exemplo. 


\section{REFERÊNCIAS}

ANEXOS. Rev. Cadernos para o professor, out. 2003. p. 88-94.

ANTUNES, R. Adeus ao trabalho? Ensaio sobre as metamorfoses e a centralidade do mundo do trabalho. 7. ed. São Paulo: Cortez. Campinas, SP: EVEC, 2000.

CARVALHO, Mauri. A miséria da educação física. Campinas, SP: Papirus, 1991.

CBCE (Org.). Educação física escolar frente a LDB e aos PCNs: profissionais analisam renovações, modismos e interesses. Ijuí, RS: Sedigraf, 1997.

COLETIVO DE AUTORES. Metodologia no ensino da educação física. São Paulo: Cortez, 1992.

CULLAR, Ferreira. Cultura popular. In: FAVERO, O. (Org.). Cultura popular, educação popular: memória dos anos 60 . Rio de Janeiro: Graal, 1990.

ESCOBAR, M. O.; TAFFAREL, C. Z.; SOARES, C. L. A educação física escolar na perspectiva do século XXI. In: MOREIRA,W. W. (Org.). Educação física e esportes: perspectivas para o século XXI. Campinas, SP: Papirus, 1995.

FORRESTER, V. O horror econômico. São Paulo: UNESP, 1997.

FRANCO, M. C. Formação profissional para o trabalho incerto: um estudo comparativo Brasil, México e Itália. In: FRIGOTTO, G. (Org.). Educação e crise do trabalho: perspectiva de final de século. Petrópolis, RJ: Vozes, 1998.

FREIRE, Ana M. Analfabetismo no Brasil. 2. ed. São Paulo: Cortez, 1993.

FREITAS, Luiz C. Crítica da organização do trabalho pedagógico e da didática. 6. ed. Campinas: Papirus, 2003.

FRIGOTTO, G. Educação e a crise do capitalismo real. 2. ed. São Paulo: Cortez, 1996. 
FRIGOTTO, G. Os delírios da razão: crise do capital e metamorfose conceitual no campo educacional. In: GENTILI, P. (Org.) Pedagogia da exclusão: crítica ao neoliberalismo em educação. 4. ed. Petrópolis, RJ: Vozes, 1998.

Educação e crise do trabalho: perspectivas de final de século. 5. ed. Rio de Janeiro: Vozes, 2001.

. Teoria e educação no labirinto do capital. Petrópolis, RJ: Vozes, 2001.

HOBSBAWM, E. O novo século: entrevista a Antonio Polito. São Paulo: Cia. das Letras, 2000.

KOSIK, Karel. Dialética do concreto. 6. reimp. São Paulo/ Rio de Janeiro: Paz e Terra, 1995.

KUENZER, Acácia. Educação e trabalho no Brasil: o estado da questão. Brasília, INEP/MEC, 1987.

Ensino de $2^{\circ}$ grau: o trabalho como princípio educativo. São Paulo: Cortez, 1988.

MANACORDA, M. A. Marx e a pedagogia moderna. Campinas, SP: Cortez; A. Associados, 1991.

MARX, Karl; ENGELS, F. Crítica da educação e do ensino. Lisboa: Moraes, 1978.

A ideologia alemã. 11. ed. São Paulo: Hucitec, 1999.

MESZÁROS, István. O século XXI: socialismo ou barbárie? São Paulo: Boitempo, 2003.

MINAYO, Maria Cecília S. O desafio do conhecimento: pesquisa qualitativa em saúde. 6. ed. São Paulo; Rio de Janeiro: Hucitec, Abrasco, 1999.

NEVES, L. Brasil 2000: nova divisão de trabalho na educação. São Paulo: Xamã, 2000.

OLIVEIRA, F. Privatização do público, destituição da fala e anulação da política: o totalitarismo neoliberal. In: OLIVEIRA, F.; PAOLI, M. C. (Orgs.). Os sentidos da democracia: políticas do dissenso e hegemonia global. 2. ed. Petrópolis, RJ: Vozes; Brasília: NEDIC, 1999. 
OLIVEIRA, V. M. Consenso e conflito da educação física brasileira. Campinas, SP: Papirus, 1994.

PAULA SILVA, M. C.; ZACARIAS, L. S. et alli. Programa municipal de educação física: diretrizes curriculares. Juiz de Fora/MG: PJF/ Helvética, 2000.

PAULA SILVA, Maria Cecília. Projeto Práxis: PJF/MG. 1999. Texto mimeo.

Da educação física, moral e intelectual a um corpo idealiza$d o$ : desvelando o discurso médico nas teses da Faculdade de Medicina do Rio de Janeiro. (Tese de Doutorado). Rio de Janeiro: PPGEF/UGF, 2002.

Ensino de Educação Física. Rev. Cadernos do professor: edição especial. Ano XI, Juiz de Fora, PJF, out., 2003.

A legitimidade da educação física escolar: confrontos e desafios. Rev. Cadernos do Professor. Abi XII, n. 13, Juiz de Fora, PJF, mar, 2004.

SADER, Emir. A vingança da história. São Paulo: Boitempo, 2003.

SOARES, C. L. Educação Física: raízes européias e Brasil. Campinas: Autores Associados, 1994.

TAFFAREL, Celi N. Z. As propostas pedagógicas e sua aplicação na realidade escolar. In: Anais do IV EnFEFE: Planejando a Educação Física na escola. Niterói: UFF, 2001.

A história nos currículos de formação de profissionais/professores de Educação Física e Esporte: disciplina curricular x matriz científica. In: Anais: Congresso Brasileiro de História da Educação Física, Esporte, Lazer e Dança. Porto Alegre: UFRGS, 2000.

Recebido: 30 de abril de 2004 Aprovado: junho de 2004

Endereço para correspondência Rua Miguel Calmon s/n.

Vale da Canela - Salvador - Bahia CEP 40110-100

E-mail: cecilipaula@ufba.br. 